\title{
Mídia e inovação em Simmel, Benjamin e McLuhan
}

\section{Media and innovation in Simmel, Benjamin and McLuhan}

\author{
Antonio Rafele ${ }^{1}$ \\ Doutor em Sociologia, pesquisador do Centro de Pesquisa Internacional ATOPOS, Universidade de São Paulo, e do Centro \\ de Estudos sobre o Atual e o Cotidiano, CEAQ, Universidade Paris Descartes La Sorbonne. Entre suas publicações estão \\ Representations of Fashion: The metropolis and mediological reflection between the nineteenth and the twentieth centuries \\ (San Diego University Press, 2013). \\ <antonio.rafele@gmail.com>
}

\section{RESUMO}

Este artigo pretende investigar as correlações textuais que conjugam o pensamento de Simmel (Philosophie des Geldes e Die Grosstädte und das Geistesleben), Benjamin (Das Passagen-Werk) e McLuhan (Understanding Media) em uma reflexão comum em torno das modalidades de inovação tecnológica. A partir de uma leitura dos textos, a reflexão desdobrase em três momentos complementares: a reconstrução da tradição acima mencionada, realizada por meio de uma abordagem focada nos traços de continuidade que ligam em um corpus orgânico os três autores; um exame sobre o conceito de medium e suas implicações epistemológicas; o caso emblemático, concernente ao tema da inovação tecnológica, da fotografia. Os elementos que emergem dessa reflexão - medium e percepção, medium e tempo, medium e hábito, medium e formas sociais - evidenciam uma ideia de comunicação fundada sobre uma nova imagem de história e natureza, verificadas em sua recíproca relação de simulação e exclusão.

Palavras-chave: Medium. Novitas. Cotidiano.

\begin{abstract}
This paper aims to investigate the textual relations that link the thought of Simmel (Philosophie des Geldes and Die Grosstädte und das Geistesleben), Benjamin (Das Passagen-Werk) and McLuhan (Understanding Media) in terms of a common reflection on modes of technological innovation. Through a close reading of the texts, the reflection unfolds in three complementary parts: the reconstruction of the tradition mentioned above, accomplished through a focus of the traits of continuity that tie into an organic corpus of the three authors; a survey on the concept of medium and his epistemological implications; the case of photography, emblematic, in this study, for the technological innovation. The elements which arise from this reflection - medium and perception, medium and time, medium and habits, medium and social forms - show in detail an idea of communication based on a new image of history and nature, observed in their mutual relation of competition and exclusion.
\end{abstract}

Keywords: Medium. Novitas. Everyday life.

\section{Origem: textos e autores}

O estudo das relações entre tecnologia e inovação permite a construção de um modelo de análise que pudesse definir os conceitos e processos típicos da inovação tecnológica, oferecendo um conjunto complexo de conceitos

1 Este artigo é parte de uma pesquisa de pós-doutorado realizada com bolsa de FAPESP no período 2013-2015 na ECA-USP, no interior do Centro de Pesquisa Internacional ATOPOS, sob a supervisão do Prof. Dr. Massimo Di Felice. 
baseado num percurso histórico sobre as mídias, do século XIX ao XXI, e uma série de indicações teórico-metdológicas para o estudo e a compreensão da qualidade das transformações em ato nas práticas digitais. Tal paradigma é constituído pelas obras de Georg Simmel, Walter Benjamin e Marshall McLuhan, dos quais incidiram sobre a relação entre a experiência cotidiana e o repertório metodológico, as relações entre medium e território, medium e percepção, medium e estruturas sociais, medium e história. Esta tradição é vista como um corpus homogêneo, caracterizada por uma matriz epistemológica comum, ou pela coincidência entre método e análises específicas, que rende um unicum originário e incindível entre tecnologia e formas da experiência. Articulam-se a esse propósito três excertos significativos As Grandes Cidades e a Vida do Espírito (1903), A obra de arte na era de sua reprodutibilidade técnica (1935) e Os meios de comunicação como extensões do homem (1964):

A metrópole volta a uma das maiores tendências de desenvolvimento da vida social como tal, a uma das poucas tendências para as quais pode ser descoberta uma fórmula aproximadamente universal. A função da metrópole é de fornecer um espaço para a criação, o contraste e as tentativas de conciliação entre as diversas tendências (Simmel, 2009, 1, p. 18).

No interior de grandes períodos históricos, a forma de percepção das coletividades humanas se transforma ao mesmo tempo que seu modo de existência. O modo pelo qual se organiza a percepção humana, o meio em que ela se dá, não é apenas condicionado natural, mas também historicamente (Benjamin, 2014, p. 49).

Numa cultura como a nossa, há muito acostumada a dividir e estilhaçar todas as coisas como meio de controlá-las, não deixa, às vezes, de ser um tanto chocante lembrar que, para efeitos práticos e operacionais, o meio é a mensagem. Isto apenas significa que as conseqüências sociais e pessoais de qualquer meio - ou seja, de qualquer uma das extensões de nós mesmos - constituem o resultado do novo estalão introduzido em nossas vidas por uma nova tecnologia ou extensão de nós mesmos. Pois a "mensagem" de qualquer meio ou tecnologia é a mudança de escala, cadência ou padrão que esse meio ou tecnologia introduz nas coisas, humanas. A estrada de ferro não introduziu movimento, transporte, roda ou caminhos na sociedade humana, mas acelerou e ampliou a escala das funções humanas anteriores, criando tipos de cidades, de trabalho e de lazer totalmente novos. 


\begin{abstract}
"O meio é a mensagem", porque é o meio que configura e controla a proporção e a forma das ações e associações humanas. O conteúdo ou usos desses meios são tão diversos quão ineficazes na estruturação da forma das associações humanas (McLuhan, 1996, p. 20-21).
\end{abstract}

De acordo com tais perspectivas, a tecnologia não é um setor específico da vida social, mas o lugar no interior do qual nasce, advém e articulam-se as diferentes potencialidades da história. Entre sujeito e objeto não se estabelece uma relação funcional ou hierárquica, mas uma coincidência: à metrópole devem-se as principais tendências psicológicas, sociais e políticas do século XIX (intelecto, produção, consumo, distração, moda, cultura objetiva e subjetiva, identidade, estilo de vida, grupos sociais restritos e alargados) e enquanto à eletricidade devem-se serem reconduzidos os traços dominantes do presente (próteses, hábitos e vícios, fluxos, efêmero e globalidade). Como as citações abaixo demonstram, segue-se, em termos operacionais, que a tecnologia deve ser estudada sobre as configurações atuais e cotidianas para além de qualquer juízo positivo ou negativo.

Entretanto, neste processo, as correntes da vida, quer seus fenômenos individuais nos toquem de forma simpática, quer de forma antipática, transcendem inteiramente a esfera para a qual é adequada a atitude de juiz. Uma vez que tais forças da vida se estenderam para o interior das raízes e para o cume do todo da vida histórica a que nós, em nossa efêmera existência, como uma cédula, só pertencemos como uma parte, não nos cabe acusar ou perdoar, senão compreender (Simmel, 2009, 1, p. 25).

Método deste trabalho: montagem literária. Não tem nada mais a dizer. Só de mostrar. Não retirarei nada de precioso e não me apropriarei de alguma expressão engenhosa (Benjamin, 2007, p. 167).

Decifrar as configurações [...] Eé só dessa forma que se pode individuar os princípios e as linhas de força do medium (McLuhan, 1996, p. 75).

Simmel, Benjamin e McLuhan formam, ao lado de outras escolas dominantes, uma teoria unitária da comunicação seja sobre o plano do método que sobre aquele dos conceitos e das imagens. Oferecem também um 
percurso histórico articulado por etapas e passagens essenciais da sucessão de inovações tecnológicas entre os séculos XIX e XX: o nascimento e a afirmação das metrópoles, a difusão e o poder da fotografia, o advento do cinema e da televisão, o mundo das redes. Trata-se de um fundo de tal forma rico a permitir hoje, mediante um olhar retrospectivo, isolar e visualizar os mecanismos e as estruturas fundamentais que repetidamente acompanham o aparecimento e a afirmação de um novo medium. A construção de um paradigma, realizada através da investigação de nosso passado recente, tem a função de iluminar algumas operações específicas do mundo das redes, inserindo este último no interno de um longo processo histórico que começou com a metrópole e culminou agora no advento das mídias digitais. Refiro-me, em particular, às relações entre medium, percepção e forma comunicativas do Habitar, objeto dos estudos de Massimo Di Felice (2009 e 2012); as relações em mídia e processos históricos analizados nos textos de Henry Jenkins (2006); a forma, as circunstâncias e a persona na reflexão pós-moderna de Maffesoli (1988 e 1990); as relações entre medium e dimensão pós-humana nos textos de Alberto Abruzzese (2003 e 2015); a estética e as formas do sentir na reflexão de Mario Perniola (1994); os conflitos e as evoluções existentes entre mídia e estruturas sociais objeto dos volumes de Manuel Castells (2001).

\section{$O$ conceito de medium}

Em Benjamin, Simmel e McLuhan o conceito de medium revela, por um lado, a estreita dependência que existe entre o plano da reflexão teórica e aquela da análise direta dos objetos, entre teoria e técnica, do outro, a imagem da expereincia como repentina manifestação de subjeto e objeto. Por este plano de observação a inovação tecnologia assume uma relevância essencial: ao novo medium corespondem ulteriores formas de vida e, ao mesmo tempo, as imagens do observador.

\footnotetext{
Se o efeito, que um elemento exerce sobre um outro, torna-se a causa do efeito reflexo que o último exerce sobre o primeiro, de modo que por sua vez torna-se de novo causa de um efeito de retorno, fazendo iniciar novamente todo o jogo, se dá aqui o modelo de uma verdadeira e própria atividade ao infinito. Esta imanente infinidade é comparável àquela do círculo (Simmel, 2009, 2, p. 54).
} 
O que torna as primeiras fotografias tão incomparáveis talvez seja isto: elas representam a primeira imagem do encontro entre a máquina e o homem [...] Todas as grandes conquistas no domínio das formas não se deram afinal assim, como descobertas técnicas? Começamos apenas recentemente a adivinhar quais formas, que se tornarão determinantes para a nossa época, estão ocultas nas máquinas (Benjamin, 2007, p. 720).

Se abrirmos um número da Life de 1938, as imagens e as poses que acreditávamos normais parecem ainda mais coisas remotas mais que os objetos realmente antigos. As crianças de hoje usam a expressão "os velhos tempos", aplicando-a aos cabelos e às galochas de ontem, tanto profundo que é o seu acordo às abruptas mudanças sazonais do comportamento visivo introduzido pela moda. Mas a experiência fundamental resume-se naquilo que sente a maioria das pessoas para o jornal do dia anterior: a sensação de que nada pode ser mais totalmente fora de moda. Os músicos de jazz expressam o seu desgosto pelo jazz gravados em discos dizendo: É obsoleto como o jornal de ontem (McLuhan, 1996, p. 82).

A partir da experiência da metrópole, da moda e da fotografia, aqui unidas como vetores de uma extraordinária aceleração do tempo, que rompe a duração e a estabilidade das coisas, até o ponto de constituir um único bloco temporal do observador, se ganha um ponto de vista sobre a natureza fragmentária do vivido, que esses dois trechos de Benjamim e de McLuhan tornam evidentes:

A questão de como este ser agora (que é algo diverso do ser agora do "tempo de agora", já que é um ser agora descontínuo, intermitente) já significa em si uma concretude superior, entretanto, não pode ser apreendida pelo método dialético no âmbito da ideologia do progresso, mas apenas numa visão da história que ultrapasse tal ideologia em todos os aspectos. Aí se deveria falar de uma crescente condensação (integração) da realidade, na qual tudo o que é passado (em seu tempo) pode adquirir um grau mais alto de atualidade do que no próprio momento de sua existência. $O$ passado adquire 0 caráter de uma atualidade superior graças à imagem como a qual e através da qual é compreendido. Esta perscrutação dialética e a presentificação das circunstâncias do passado são a prova da verdade da ação presente. Ou seja: ela acende o pavio do material explosivo que se situa no ocorrido - cuja figura autêntica é a moda (Benjamin, 2007, p. 436). 
Não é talvez evidente que não apenas a sequência dá lugar a simultaneidade, se entra no mundo da estrutura e da configuração? [...] Isso não era de todo óbvio antes da velocidade elétrica e do campo total. Parecia então que a mensagem fosse o "conteúdo" e as pessoas costumavam a se perguntar o que significava representar um quadro, mesmo se não colocava esta pergunta a propósito de uma melodia, uma casa ou de um vestido, uma vez que para estas coisas se conservava um certo sentido do esquema geral, ou seja, a unidade entre forma e função (McLuhan, 1996, p. 20).

A experiência não permite inferir a priori, mas ocorre naquelas formas que nelas produzem uma exposição atual. Os pontos fortes, os detalhes e as minúcias, as variações e as nuances, da experiência residem em similares configurações, que têm e mostram em uma única tensão formal todos os aspectos do vivido. Adentrando-se, em seguida, à desconstrução das linhas de força que contradizem um dado medium, o observador adquire uma distância tal capaz de adquirir uma imagem completa, embora provisória, dos processos pelos quais é atravessado. Como Understanding media, nas secções dedicadas à moda ou à fotografia, ou ainda à televisão, assim, em Metropóles de Simmel e em Passagens de Benjamin, o leitor visualiza uma tensão entre o observador e o medium, que se configura como o momento originário do conhecimento. Nestas representações, que não possuem uma tensão classificatória, mas a forma de uma constelação orgânica do observador, o leitor se adentra na matéria, sem nunca ser capaz de distinguir as imagens históricas daquelas do pensamento. Na linguagem ou na escrita, as ideias e os fenômenos formam um único movimento, e chegam a uma exposição "aberta" para o leitor. Somente dentro deste caminho, detalhado e fragmentário, em que partes individuais mostram ao máximo grau a matéria e se co-penetram a posteriori, é dado para o observador alcançar uma imagem completa pela reflexão. O leitor agarra em um instante aquele emaranhado de problemas, e por identificação reconhece, mas sob uma outra luz, os momentos da experiência vivida.

Em particular, sobre o plano da análise, o presente é uma nova e irredutível curva da história que recupera, para uso próprio e consumo, algumas partes de um passado que entende como útil, necessário ou próximo. Mais do que cronológica, e em perfeita analogia com a Moda, a vizinhança é uma proximidade estilística. Por exemplo, na televisão convivem elementos que lhe são inerentes (transmissão ao vivo, núcleo doméstico) e elementos subtraídos a outros âmbitos da vida contemporânea; não os engloba de forma linear, preferindo decompô-los e recompô-los segundo as próprias exigências: as 
séries televisivas são uma outra coisa relativamente aos filmes projetados no cinema, os telejornais uma remota citação da imprensa. Os discursos políticos, à semelhança daqueles científicos, interiorizam a encenação espetacular até se transformarem em discursos publicitários, a projeção "ao vivo" dos eventos desportivos modifica o próprio modo de se praticar e conceber o desporto.

As formas da história não são autónomas entre si, mas estão sujeitas a reconfigurações imprevistas. De facto, o aparecimento de um novo evento pode incidir com profundidade, reconfigurando o sistema ou uma parte dessa. O cinema, com a chegada da televisão, encontra-se diante de uma bifurcação: explorar outras dimensões expressivas ou limitar-se a uma produção funcional ao público televisivo. Um processo análogo é o da tentativa por parte da televisão (mas também do cinema) em seguir as narrações dos videojogos e as modalidades comunicativas das redes (veja-se a diversificação da televisão através dos inúmeros canais de satélite). A novidade, ao surgir, é uma nova e ulterior fantasmagoria que alimenta desejos, expectativas e potencialidades expressivas totalmente específicas, e que as formas já existentes não são capazes de satisfazer. O inexorável avanço do novo, a sua vida quotidiana, a sua ramificação, transforma automaticamente em ruínas as formas anteriores, obrigando-as a uma competição que comporta ou uma marginalização das mesmas ou um esgotamento das suas potencialidades expressivas. Sob o ponto de vista social, o indivíduo, e eventualmente a coletividade, vivem a novidade na forma anfíbia do desejo e do medo, na qual o desejo reflete a vontade de se libertar na inovação à procura de novos prazeres e sensações, enquanto o medo surge ligado às ânsias e angústias pelas mudanças que o medium determina ou determinará quanto aos equilíbrios existentes. Medo e desejo caracterizam a fase inicial de interiorização; são uma espécie de propriedades ou figuras que o "eu" usa para nomear o exterior. A fase seguinte é a da dependência quotidiana: o corpo social entra no medium, entorpece-se, adquire desse ritmos e potencialidades, construtivas ou destrutivas quais sejam, até aceitá-lo e saturálo.

Ao nascimento de um novo medium corresponde, na consciência, a multiplicação de imagens ideais, nas quais o indivíduo e a coletividade tentam não só eliminar a imperfeição do produto bem como os defeitos do sistema social.

À forma do novo meio de produção, que no início ainda é dominada por aquela do antigo (Marx), correspondem na consciência coletiva imagens nas quais se interpenetram o novo e o antigo [...] Ao lado 
disso, nestas imagens de desejo vem à tona a vontade expressa de distancia-se daquilo que se tornou antiquado - isso significa, do passado mais recente. Estas tendências remetem a fantasia imagética, impulsionada pelo novo, de volta ao passado mais remoto. No sonho, em que diante dos olhos de cada época surge em imagens a época seguinte, esta aparece associada a elementos da história primeva, ou seja, de uma sociedade sem classes. As experiências desta sociedade, que têm seu depósito no inconsciente do coletivo, geram, em interação com o novo, a utopia que deixou seu rastro em mil configurações da vida, das construções duradouras até as modas passageiras (Benjamin, 2007, p. 41).

Inicialmente a novidade aparece-nos como um angelus novus, uma circunstância prestes a transformar-se em ato ou prática quotidiana porém ainda informe, ao estado nascente e em potência. Nesta fase, o novo assume uma face paradoxal e dupla: por um lado mostra-se um reflexo ou uma derivação do velho (nas suas primeiras manifestações a fotografia faz vir à memória a pintura, o cinema, a literatura, as metrópoles, a pequena cidade, as redes, a televisão); por outro lado alimenta desejos e expetativas, potencialidades políticas e sociais que exigem ser totalmente implantadas, destruindo, se para tal for necessário, os laços e as cesuras colocadas pelo sistema na tentativa de controlar a sua expansão . Paralelamente é criado, sob o plano imaginário, uma lacuna entre "presente" e "passado próximo"; lacuna que absorve e alimenta a necessidade, própria de todas as gerações, de se distanciar da época imediatamente precedente: "Cada geração vivencia a moda da geração imediatamente anterior como o mais radical dos antiafrodisíacos que se pode imaginar (Benjamin, 2007, p. 117)". A fim de impor a sua diferença e originalidade, o novo elabora uma série de discursos que remetem a fantasia, individual e coletiva, para um passado antiquíssimo, ao sonho em que a sociedade reaparece na sua forma originária, despida de qualquer vínculo social, divisão em classes ou atores sociais. Trata-se de discursos que representam o homem num estado idílico, pleno de humanidade, porém abstrato e de todo descontextualizado. Provisórias suspensões da vivência e dos equilíbrios sociais a que correspondem sensações ou ilusões de que a própria necessidade dos equilíbrios possa ser definitivamente superada. Na verdade, as utopias estão apenas aparentemente desprendidas do presente mas, na realidade, são um prolongamento senão mesmo uma arma. $O$ último objetivo desse não é tanto a realização do projeto quanto o aperfeiçoamento das novidades: "dar um aspeto mais humano às máquinas". As utopias pertencem a uma fase dormente ou subconsciente, 
perduram até à definitiva entrada do novo no dia-a-dia de cada um. A novidade passa de potencialidade a ato e transforma-se numa "máquina operativa", capaz de integrar os objetivos originários - comércio, lucro, consumo - e as exigências de humanidade originadas in itinere. É criada aquela condição, provisória mas repetida ao longo do tempo, segundo a qual a coletividade, ou parte dessa, vivencia a chegada da novidade num estado dormente e alucinatório até à sua definitiva afirmação social. A transformação do mito em habitus, da força cega e pulsional em circunstância clara, delineada e indissolúvel do agir, vê a simultânea redefinição das funções, dos valores e dos poderes de diferentes atores sociais.

No seu todo a história apresenta-se como uma sucessão, potencialmente infinita, de instantes presentes, mas também imediatamente "já passados". Entre cada evento não é estabelecida qualquer linearidade ou progressividade, bem pelo contrário, denota-se um salto, uma descontinuidade diretamente proporcional no que diz respeito à diferença técnica que os separa. A novidade constitui a afirmação de um novo e irredutível fragmento da história e, ainda, uma ulterior e irreversível quebra da mesma. Os fragmentos são tais e essencialmente isolados, sucedem-se em modo descontínuo e nunca formarão uma totalidade: em primeiro lugar não há qualquer vaso, e depois, que nós saibamos, não existe nenhuma consciência, conhecimento ou acesso. 0 momento originário e criativo não reside num hipotético fragmento mãe que engloba todos os outros, mas coincide com aquele instante fulminante, salto, em que surge um novo evento. No momento do seu aparecimento, a novidade origina imediatamente história, ação e, como tal, impulsiona a uma experiência do sagrado, entendido não como recinto de um laço religioso regulado, mas como evento capaz de quebrar o curso do tempo, entregando assim uma nova e ulterior possibilidade de vida.

A história enquanto sucessão de eventos e hábitos é uma imagem da história que exclui qualquer sentido de fim ou de finalidade do tempo e, que, pelo contrário, reconhece o prazer e a vontade de viver como única necessidade deveras essencial. Os eventos oferecem um estilo de vida; por sua vez, o prazer justifica e contém a sua inumerável multiplicação. À imagem e reflexo da Moda, a história exibe um tempo circular, extensível até ao infinito.

Nascimento e morte [...] limitam consideravelmente a margem de liberdade da moda, quando se tornam atuais, este estado de coisas é realçado por uma dupla circunstância. A primeira refere-se ao nascimento e mostra como a recriação natural da vida é "superada" 
pela novidade no domínio da moda. A segunda refere-se à morte. No que concerne á morte, ela não aparece menos "superada" na moda, quando esta liberta o sex appeal do inorgânico (Benjamin, 2007, p. 117).

O eu conserva, supera e experiencia o nascimento e a morte mediante apenas das projeções, ilusão e desilusão, que recordam, transfiguram e simulam o seu ritmo. Acaba por se criar uma bifurcação entre tempo biológico e tempo da história: tempo natural é constituído pelo fluxo do nascimento, do envelhecimento e da morte física, um processo "já estabelecido" em que o eu se absorve desdeo primeiromomento epor toda a sua experiência, queoimpulsiona e exige estar continuamente ocupado porquanto é vazio, homogéneo; a história aparece como uma invenção do eu, uma dimensão paralela destinada a simular o funcionamento da natureza mas, sobretudo, artificial e ilusória. A história prossegue, ao insuflar-se e ao produzir infinitas temporalidades, mundos virtuais, através dos media (passados ou presentes) de que dispõe, e constitui uma segunda natureza que atrai e distrai o eu do fluxo vazio e homogéneo do tempo natural, instaurando, por conseguinte, um conjunto de mecanismos internos tais como a citação, a memória, a remoção, o renascimento, o fim, o sucesso, a queda, a dor, o ritmo, o desempenho. Enquanto sucessão infinita e intermitente de eventos torna-se ainda num sistema ingovernável ou assimilável segundo uma única perspetiva, na medida em que a cada ponto dessa correspondem configurações e estados mentais completamente irredutíveis. A vida traduzse em eventos concretos ou imaginários: polis, filosofia, metrópoles, trabalho, filmes, romances, videojogos. Em ambos os casos o eu executa o mesmo tipo de experiência : uma imersão no objeto que produz, por sua vez, uma distração do tédio e da inexorável passagem do tempo. As formas, as coisas, as ideias e os eventos geram e amplificam o prazer ou a felicidade, que está sempre prestes a desmoronar-se no nada ou no desespero que esconde; é precisamente este vazio que se constitui como origem e instinto fundador da história, sob a forma de insuperável necessidade de distração. A constante oscilação entre distração e vazio deixa entrever que o eu é sempre e apenas viciado e nunca realiza uma experiência sensível do nascimento e morte biológicas, instantes imediatos dos quais não se tem qualquer consciência ou conhecimento. A própria morte é imaginada como forma máxima de distração, como um evento que repentinamente distrai e recoloca num outro e indizível território.

Nestes três autores a ideia de medium se declina, embora com ênfases distintas, como a de inovação segundo a seguinte síntese. Cada medium introduz 
específicas transformações no espaço e no tempo e da condição habitativa (se pensamos as metrópoles a respeito da cidade pequena ou a fotografia respeito à pintura). Cada medium modifica os modos e as formas da percepção sensorial (emblemático o caso da televisão e a sua influência sobre os sentidos da vista e do tato). Cada medium ativa práticas e hábitos que reconfiguram tanto o funcionamento psíquico individual (intelecto, sentimento, identidade, estilos de vida) quanto a forma da estrutura social essencial (esfera pública e privada, grupos sociais, produção e consumo, opinião e imaginário). Cada medium estabelece relações com um passado a ele próximo, tal vínculo aparece guiado pelos conceitos de simultaneidade, descontinuidade atualização. Cada medium modifica o sistema das tecnologias pré-existentes, desgastando e superando-as (se pensamos com as redes estão tornando obsoletas as formas precedentes de organização, conservação e transmissão das informações). Cada medium é vivido pela coletividade segundo uma fenomenologia que prevê uma dupla fase: da primeira uma atitude de medo e desejo em direção ao novo, sucessivamente uma progressiva dependência cotidiana (tal dependência expõe tanto os pontos de força quanto de insuficiência, as fraquezas e os possíveis pontos de ruptura).

\section{Fotografia, primeiro medium}

"O que torna as primeiras fotografias tão incomparáveis talvez seja isto: elas representam a primeira imagem do encontro entre a máquina e o homem (Benjamin, 2007, p. 720)". Ao apresentar-se como primeiro medium, a fotografia realiza cenários, situações, práticas e crenças diretamente proporcionais com as capacidades técnico-expressivas de que dispõe. Cria, de igual modo, um desvio relativamente ao modelo renascentista de fruição ligado, por sua vez, quer às distinções entre cultura alta e cultura baixa, quer à conceção da obra como experiência de sentido, cujas duração e existência iam muito para além do fruidor. Com a fotografia é o próprio medium que ativa conteúdos e organizações sensoriais, e fá-lo não no papel de instrumento de ideias ou desejos extrínsecos, mas em virtude das suas próprias potencialidades. Se por um lado o medium gera costumes que o eu metaboliza e repete, por outro a sua duração coincide com aquela do seu próprio consumo. O fruidor torna-se numa articulação orgânica do medium, pois é só através da receção e do uso que ele existe ou vive.

Como nova criação ab nihilo, do nada, a fotografia possui a característica de isolar cada fragmento no tempo, e de isolar não apenas as coisas mas também as pessoas com uma espécie de olhar distante e omnicompreensivo, 
quase em posição de superioridade. Ao cristalizar momentos pontuais, a fotografia distingue-se da escultura clássica, que, por sua vez, almejava a duração e a atemporalidade. Cada instante imortalizado pela fotografia passa automaticamente a pertencer ao passado ou revela-se como morto; por isso, quem se revê em imagem entra numa relação direta com uma experiência de morte, com o que já foi. Cada fotografia é representação de um instante que condensa em si um período da história do mundo e não há qualquer linearidade ou progressão entre duas fotografias mas sim uma intermitência, uma descontinuidade. A vida parece realizar-se numa sucessão de momentos imediatamente "já passados", como se uma linha se rompesse de forma constante em pequenos segmentos, suspensos e autónomos, que fecham em si um inteiro período ou intervalo temporal.

Estas modificações traduzem-se numa nova perceção da existência, agora entendida como sucessão de imersão e retorno: vive-se uma experiência e, quando essa se esgota, volta-se a pensar nessa através de uma espécie de visão póstuma ou retrospetiva. Imersão, emersão e atraso póstumo constituem concomitantemente um processo experiencial, mnemónico e cognitivo que caracteriza a relação com as coisas. À luz de um olhar para trás, as coisas do mundo serão percebidas como ilusões, hábitos, vícios que absorvem e ocupam, não somente por determinados períodos, o tempo do eu. A morte irrompe no dia-a-dia, não sob a forma de morte biológica ou experiência incomunicável e marginal relativamente às inúmeras distrações e vícios, mas como experiência de caducidade. As coisas mostram simultaneamente a dupla face da vitalidade e da ruína; a sensação de vitalidade anda de mãos dadas com aquela desoladora de ruína e juntas permeiam em profundeza o tempo do eu. À oposição vida/ morte, que previa uma rígida demarcação entre as duas experiências - e a qual garantia a centralidade do mito da imortalidade - se sobrepõe um estado de circularidade vida-morte; nesse o valor da duração é fraco e quase nulo e a memória assume-se como a única capacidade de resistência no que toca à ação corrosiva e destruidora do tempo. Sobre o surgimento da fotografia:

\footnotetext{
A tecnologia da comunicação diminui os méritos informativos da pintura. Ademais, prepara-se uma nova realidade, diante da qual ninguém pode assumir a responsabilidade de uma tomada de posição pessoal. Apela-se à objetiva da câmera. A pintura, por sua vez, começa a acentuar a cor (Benjamin, 2007, p. 721).
} 
Enquanto novo evento do mundo, a fotografia, por um lado, desencadeia processos de todo inéditos e, por outro, recupera e consente uma releitura de elementos do passado. Entrando em pormenor, algumas formas - ligadas ao crescente poder adquirido pelo luxo como vetor de uma perceção materialística do mundo - que remontam aos séculos XV, XVI e XVII, aparecem, à luz do novo medium, como antecedentes da fotografia. Na Época Medieval a imagem era objeto de disputas teológicas ou filosóficas, ao passo que a partir do Renascimento, ao afirmar-se um novo estilo de vida, essa é usada para expor o "visível enquanto tal", e já não é entendida como "símbolo do invisível". A imagem surge assim pré-fotográfica, na medida em que possui uma vocação para mostrar. Os frescos de Masaccio da Capela Brancacci (1425) em Santa Maria del Carmine, em Florença, podem ser considerados emblemáticos desta vocação, dado que neles a Verdade coexiste com uma dimensão exclusivamente comunicativa que se instaura entre o objeto e observador. As composições dessa época começam a fazer regredir, em plano de fundo, figuras que nos remetem à tradição cristã, ao se concentrarem na suntuosidade dos vestidos e dos tecidos, na contemporaneidade e na riqueza das mercadorias. O objetivo não é transmitir determinados conteúdos ao espetador, mas muito mais simplesmente fascinálo e capturá-lo através da exibição dos objetos quotidianos. A pintura recolhe e interioriza as coisas do mundo, não sob a forma de significantes da história sacra, mas como objetos que brilham por uma luz própria, sem quaisquer significados recônditos - religiosos ou morais - e que são capazes de viverem para além do fruidor e do momento em que ocorre essa fruição.

A fotografia mete em curto-circuito, "no presente", a posição e o funcionamento das artes tradicionais: o pintor já não pode pintar num modo realístico ou 'fotográfico', enquanto o pintor não pode mais descrever objetos ou acontecimentos aos leitores, uma vez que esses já se encontram informados pelas fotos, jornais, filmes e rádio. Ante o público e as tecnologias da metrópole, as artes tradicionais exasperam as próprias capacidades expressivas na constante procura de novos âmbitos, estilos ou conteúdos através dos quais possam obter uma pequena fatia de público e, assim, redefinir o lugar desse no mundo. A arte - o ready-made de M. Duchamp (Valeriani, 1999) - supera as suas fronteiras ao tornar-se num dispositivo comunicativo pronto para receber um novo estímulo, um novo objeto e uma nova solicitação. Já não é sistema expressivo completo e autónomo de outrora, mas produto in fieri constantemente tenso de modo a reproduzir e representar a potência e a dispersão dos fluxos quotidianos. $O$ romance - Ulisses de J. Joyce (Moretti, 1994) - cede o lugar à sobrelotação das coisas e à duração da publicidade, acolhe a intensificação da vida nervosa, a 
multiplicidade dos estímulos e das mercadorias até se transformar numa espécie de "obra mundo", por sua vez, capaz de superar os métodos, as leis e as gramáticas da arte literária e ainda aderir aos ritmos da vida metropolitana. Nestes dois momentos emblemáticos, arte e literatura sonham e antecipam a televisão (Abruzzese, 1994): com efeito, a televisão não propõe objetos completos e replicáveis mas programações, ou seja, uma sucessão de programas destinados a ocupar, sempre com mais frequência, os dias de cada um e das famílias. A obra torna-se num ininterrupto fluxo comunicativo, inclinando-se para o viewer e destinado a simular ritmos da vida quotidiana.

\section{Referências}

ABRUZZESE, A. Lo splendore della Tv. Origini e destino del linguaggio televisivo. Genova: Costa \& Nolan, 1994.

Lessico della comunicazione. Roma: Meltemi, 2003.

Punto zero. Il crepuscolo dei barbari. Roma: Sossella, 2015.

BENJAMIN, W. Origem do drama trágico alemão. São Paulo: Brasiliense, 1984.

Passagens. Belo Horizonte/São Paulo: UFMG/Imprensa Oficial do Estado, 2007.

A obra de arte na era de sua reprodutibilidade técnica. Porto Alegre: L\&PM Editores, 2014.

CASTELLS, M. The Rise of the Network Society. Oxford: Basil Blackwell, 2001.

DI FELICE, M. Paisagens pós-urbanas: o fim da experiência urbana e as formas comunicativas do habitar. São Paulo: Annablume, 2009.

DI FELICE, M.; TORRES, J. C.; YANAZE, L. K. H. Redes digitais e sustentabilidade - as interações com o meio ambiente na era da informação, São Paulo: Annablume, 2012.

JENKINS, H. Convergence Culture. New York: New York University Press, 2006.

MAFFESOLI, M. Au Creux des Apparences: Pour une Éthique de l'Esthétique. Paris: Plon, 1990.

MCLUHAN, M. The Gutenberg Galaxy: The Making of Typographic Man. Toronto: University of Toronto Press, 1962.

Os meios de comunicação como extensões do homem. São Paulo: CULTRIX, 1996. 
MORETTI, F. Opere mondo. Saggio sulla forma epica dal Faust a Cent'anni di solitudine. Torino: Einaudi, 1994.

PERNIOLA, M. II sex appeal dell'inorganico. Torino: Einaudi, 1994.

SIMMEL, G. As Grandes Cidades e a Vida do Espírito. Covilhã/Portugal: Universidade da Beira Interior, 2009.

Psicologia do dinheiro e outros ensaios. Lisboa: Ediçoes Texto \& Grafia, 2009.

VALERIANI, L. Dentro la trasfigurazione. II dispositivo dell'arte nella cibercultura. Genova: Costa\&Nolan, 1999.

Recebido em: 16/11/2016

Aceito em: 16/11/2016

Endereços do autor:

Antonio Rafele < $\underline{\text { antonio.rafele@gmail.com> }}$

Centro de Pesquisa Internacional ATOPOS

Universidade de São Paulo

Escola de Comunicações e Artes

Prédio Central 1, Av. Prof. Lúcio Martins Rodrigues, 443 - Butantã

05508-020 - São Paulo (SP) - Brasil

Centro de Estudos sobre o Atual e o Cotidiano CEAQ

Universidade Paris Descartes La Sorbonne

Centre universitaire des Saints-Pères

45 Rue des Saints-Pères

75270 Paris Cedex 06 